Article

\title{
Investigating the Influence of Meteorological Parameters on the Accuracy of Sea-Level Prediction Models in Sabah, Malaysia
}

T. Olivia Muslim ${ }^{1}$, Ali Najah Ahmed ${ }^{2, *}\left(\mathbb{D}\right.$, M. A. Malek ${ }^{3}$, Haitham Abdulmohsin Afan ${ }^{4, *(\mathbb{D} \text {, }}$ Rusul Khaleel Ibrahim ${ }^{5}{ }^{\circ}$, Amr El-Shafie ${ }^{6}$, Michelle Sapitang ${ }^{1}$, Mohsen Sherif ${ }^{7}{ }^{(1)}$, Ahmed Sefelnasr ${ }^{7}$ and Ahmed El-Shafie ${ }^{5}$ (i)

1 Department of Civil Engineering, College of Engineering, Universiti Tenaga Nasional (UNITEN), Jalan Ikram-UNITEN, Kajang 43000, Selangor Darul Ehsan, Malaysia; tikaolivia20@yahoo.com (T.O.M.); michellesapitang@gmail.com (M.S.)

2 Institute for Energy Infrastructure (IEI), Universiti Tenaga Nasional (UNITEN), Kajang 43000, Selangor Darul Ehsan, Malaysia

3 Institute of Sustainable Energy (ISE), Universiti Tenaga Nasional (UNITEN), Kajang 43000, Selangor Darul Ehsan, Malaysia; Marlinda@uniten.edu.my

4 Institute of Research and Development, Duy Tan University, Da Nang 550000, Vietnam

5 Department of Civil Engineering, Faculty of Engineering, University of Malaya (UM), Kuala Lumpur 50603, Malaysia; rusul.alqaisy@yahoo.com (R.K.I.); elshafie@um.edu.my (A.E.-S.)

6 Civil Engineering Department, Giza High Institute for Engineering and Technology, Giza 12611, Egypt; amrhuss63@gmail.com

7 Water Research Center, United Arab Emirate University, Al Ain 15551, UAE; MSherif@uaeu.ac.ae (M.S.); ahmed.sefelnasr@uaeu.ac.ae (A.S.)

* Correspondence: mahfoodh@uniten.edu.my (A.N.A.); haithamabdulmohsinafan@duytan.edu.vn (H.A.A.)

Received: 16 August 2019; Accepted: 16 October 2019; Published: 7 February 2020

\begin{abstract}
This study aims to investigate the impact of meteorological parameters such as wind direction, wind speed, rainfall, and mean cloud cover on sea-level rise projections for different time horizons-2019, 2023, 2028, 2048, and 2068-at three stations located in Kudat, Sandakan, and Kota Kinabalu, which are districts in the state of Sabah, Malaysia. Herein, two different scenarios, scenario1 (SC1) and scenario2 (SC2), were investigated, with each scenario comprising a different combination of input parameters. This study proposes two artificial intelligence techniques: a multilayer perceptron neural network (MLP-ANN) and an adaptive neuro-fuzzy inference system (ANFIS). Furthermore, three evaluation indexes were adopted to assess the performance of the proposed models. These indexes are the correlation coefficient, root mean square error, and scatter index. The trial and error method were used to tune the hyperparameters: the number of neurons in the hidden layer, training algorithms, transfer and activation functions, and number and shape of the membership function for the proposed models. Results show that for the above mentioned three stations, the ANFIS model outperformed MLP-ANN by $0.740 \%, 6.23 \%$, and $9.39 \%$, respectively. To assess the uncertainties of the best model, ANFIS, the percentage of observed data bracketed by 95 percent predicted uncertainties (95PPUs) and the band width of 95 percent confidence intervals (d-factors) are selected. The obtained values bracketed by 95PPUs are show about $75.2 \%, 77.4 \%, 76.8 \%$ and the $\mathrm{d}$-factor has a value of 0.27 , 0.21 and 0.23 at Kudat, Sandakan and Kota Kinabalu stations, respectively. A comparison between the two scenarios shows that SC1 achieved a high level of accuracy on Kudat and Sandakan data, whereas SC2 outperformed SC1 on Kota Kinabalu data.
\end{abstract}

Keywords: sea level rise; meteorological parameters; prediction; MLP-ANN; ANFIS 


\section{Introduction}

Sea levels are currently rising rapidly [1]. Sea-level rise (SLR) has been extensively discussed in the last two decades, wherein many researchers have reported that sea levels have considerably risen in the past 100 years and are rising even faster now than in the previous two millennia. Therefore, the potential impact of accelerating SLR in the 21st century has become one of the main environmental issues [2,3]. The mean sea level (MSL) in Malaysia has been rising at an unpredictable rate from 1.4 to $4.1 \mathrm{~mm} / \mathrm{yr}$ [4]. Traditional methods have been used before by previous researcher to predict sea level such as semi-empirical formulations and numerical models. However, some researchers observed certain drawbacks associated with using excessive data, which are tedious to handle and not effective for solving the problem, especially in terms of time consumption. In addition, the traditional method of the underlying systems regularly tends to become quite intractable and very difficult. If there were not enough observed data, no analysis can be achieved using these techniques. The numerical approach shows large computational costs. On the other hand, the numerical approach is deterministic, i.e., hydrodynamic equations are numerically solved in order to estimate sea levels [5]. For tide analysis, the least squares method has been applied, but there are some limitations. The problem is that the tidal characteristics are determined through minimizing the differences between a measured tidal signal and a basic sinusoidal function, which should describe unknown constituents. This method is site specific. Furthermore, if there is not sufficient observed data, no analysis can be performed using this technique. Commonly, harmonic analysis is used as a technique to predict sea levels, which allows forecasting tidal variations due to a locally modified response to astronomical forcing. Even though harmonic analysis is a powerful prediction tool, in fact, sea level variations often differ significantly from predictions. The main reason for this is that harmonic prediction does not include variations due to meteorological forcing [6-8]. Therefore, based on the statement above, two artificial intelligence techniques are proposed: a multilayer perceptron neural network (MLP-ANN) and an adaptive neuro-fuzzy inference system (ANFIS).

Three study areas located in Sabah were chosen: Kudat, Sandakan, and Kota Kinabalu. A serious SLR study is required in the coastal district, particularly in low-lying areas such as Sandakan on the eastern coast of Sabah. Kudat is a small town, but it is important for tourism. It is famous for its beaches, which are among the cleanest beaches in Sabah. However, Kota Kinabalu is the main focus in the coastal area due to its geographical location. The climate in Kota Kinabalu is classified as an equatorial climate, with high humidity, a considerable amount of sunshine, abundant rainfall, and temperatures that are relatively high and extremely invariable throughout the year. Kota Kinabalu is considered as a primary tourist destination and a major industrial and commercial center of East Malaysia [9].

\subsection{Background}

Thermal expansion and melting glaciers are the main causes of global SLR events. Recently, the focus is not only on the warming of oceans but also on how the melting of ice in Greenland plays a major role in sea-level changes globally [4]. Many factors can produce changes in the local sea level, e.g., a combination of complex processes involving meteorological parameters including atmospheric pressure, air temperature, water temperature, ocean currents, and winds [9-11].

Long-shore wind is among the most important parameters affecting sea levels on the eastern margins of the ocean [12]. The magnitude of this on SLR can vary based on location, with some places experiencing a twofold increase in SLR compared to other places. It is expected that the sea level in the Southern Ocean will be considerably affected by future changes in the wind. In contrast, most methods used for sea level forecasting do not consider the impacts of the speed and direction of the winds in transferring energy to the sea surface [13].

Winds in coastal areas are affected by an extensive range of factors operating at different space and time scales. The main local effect caused by the presence of land in the coastal zone is the orographic effect. Orographic effects are the deflection, channeling, or blocking of air flow by landforms such 
as mountains, cliffs, and high islands [14]. Wind forcing is one of the complex outcomes of many environmental factors that contribute to the variation in sea levels [15]. The rapidly changes in the direction and velocity of wind and associated in sea level changes could be the severe challenge to navigation, especially on the fairways of small fishery harbors located in river mouths, which is the center of activity of the two external forces. [16].

\subsection{Problem Statement}

Approximately $12 \%$ of the entire landmass of Malaysia is a low plain of muddy sediment, home to approximately 2.5 million people, and it is vulnerable to flooding [9]. Inundation, flooding, and erosion are the biggest impacts of SLR, particularly along the coastal area of Sandakan town [3].

Other impacts of SLR, such as changes in surface water quality, groundwater characteristics, and decline in the soil, have been reported by many researchers [17]. In addition, flooding due to these changes increases damage to life, property, and coastal habitats [18]. However, loss of tourism, recreation, and transportation functions have also been reported $[19,20]$. Thus, the range of potential physical, economic, and social impacts in Malaysia will aggravate due to SLR.

A thorough understanding of future changes in sea levels, especially near the shore, is vital for protecting coastal and low-lying regions. Predicting the changes in sea levels will have great benefits in planning and constructing coastal as well as developing and implementing ocean-based alternative energy technologies [21,22]. The majority of the existing research is focused on predicting sea-level models via conventional methods such as semi-empirical formulations and numerical models. However, some researchers observed certain drawbacks associated with using excessive data, which are tedious to handle and not effective for solving the SLR problem, especially in terms of time consumption. Furthermore, harmonic analysis is a technique for predicting sea levels that allows forecasting tidal dissimilarities. Despite this analysis being a powerful prediction tool, tidal dissimilarities often significantly differ from predictions; this is attributed to the limitations of the harmonic analysis involving meteorological parameters [6,7].

\section{Literature Review}

With rapid advancements in the field of computational technology in the last decade, the application of artificial intelligence (AI) to problems in environmental, ocean, and coastal areas has become popular with the acknowledgment of its potential in various studies. Thus, it has emerged as a powerful alternative tool in prediction modeling [23]. Some established AI techniques are artificial neural networks (ANNs), fuzzy logic, and hybrid systems, which is adaptive neuro-fuzzy inference system (ANFIS) [24]. ANN and ANFIS appear to be the most prevalent AI techniques due to their accuracy in fitting a relatively small set of data and their modest development [13]. Studies on AI techniques for SLR prediction can be found in the literature. For example, [25] applied feed-forward neural networks with three layers and the back-propagation technique to predict sea-level anomalies using the recorded local wind shear velocity data on an hourly basis at four stations near the USA coastline. Similarly, [21] applied ANN to predict sea-level variations at Hillary's Boat Harbor, Western Australia. Furthermore, [26] applied ANN, ANFIS, and the cuckoo optimization algorithm to forecast fluctuations in the water level at Chahnimeh reservoirs in southeast Iran using three important variables: evaporation, wind speed, and daily temperature. The result obtained shows that the ANFIS model performed better than the other models because it was more accurate and offers greater assurance.

Additionally, [27] employed the ANFIS model to predict Water Level Change (WLC) models of a month of hourly WLC for Yarmouth, Sain-John, and Charlottetown stations in Canadian waters, and then compared it with the results obtained using the wavelet neural network (WNN) model. The results obtained showed that the ANFIS model is superior. However, [8] employed a neuro-fuzzy inference system to predict water levels and reported that the accuracy of the model performance for an increment change in water level. High levels of accuracy and reliability can be achieved by applying ANFIS in predicting reservoir water levels three hours ahead [28]. Based on the results reported in [29], 
clearly, the ANFIS models can provide a much better performance than the Fourier series-based and autoregressive exogenous (ARX) based models in predicting monthly changes on the shoreline in northeastern Taiwan. Additionally, the nonlinearity between the input and output of the sea levels can be effectively captured using ANNs, which shows that the proposed techniques are appropriate for both short and long-term predictions of sea levels in Bulgaria [30].

Four meteorological parameters were used in both AI models-wind direction (WD), wind speed (WS), rainfall, and mean cloud cover (MCC) - which were obtained from the Malaysia Meteorological Department (METMalaysia). The monthly MSLs used herein were obtained from the Permanent Service for Mean Sea Level agency. This study has three main objectives. The first objective is to investigate the impact of WD, WS, rainfall, and MCC on SLR at three different stations. The second objective is to develop models to predict the SLR in 2019, 2023, 2028, 2048, and 2068 ahead of time. The results are presented in terms of lower limit (LL), upper limit (UL), MSL, and average change in sea level. The third objective is to compare two different algorithms, MLP-NN and ANFIS, according to two different scenarios-geological location and meteorological variables.

\section{Study Area}

Sabah is located in Malaysia on the northern portion of Borneo Island. Sabah shares land borders with the Malaysian state of Sarawak to the southwest and Indonesia"s Kalimantan region to the south. The total land area of Sabah is $~ 73,904 \mathrm{~km}^{2}\left(28,534 \mathrm{mi}^{2}\right)$; it is bordered by the South China Sea in the west, Sulu Sea in the northeast, and Celebes Sea in the southeast. Sabah is the second largest state in Malaysia and is known as the "Land below the Wind" because of its position below the typhoon belt. Kudat is located in the northernmost part of Sabah. On the west and east, it is bordered by the South China Sea and the Sulu Sea, respectively. Sandakan is located on the eastern coast of Sabah, $10 \mathrm{~m}$ above sea level and bordered by the open Sulu Sea, whereas Kota Kinabalu (KK) is the capital of Malaysia's Sabah state and is located in the northern part of Borneo Island. Figure 1 shows the stations considered in this study.

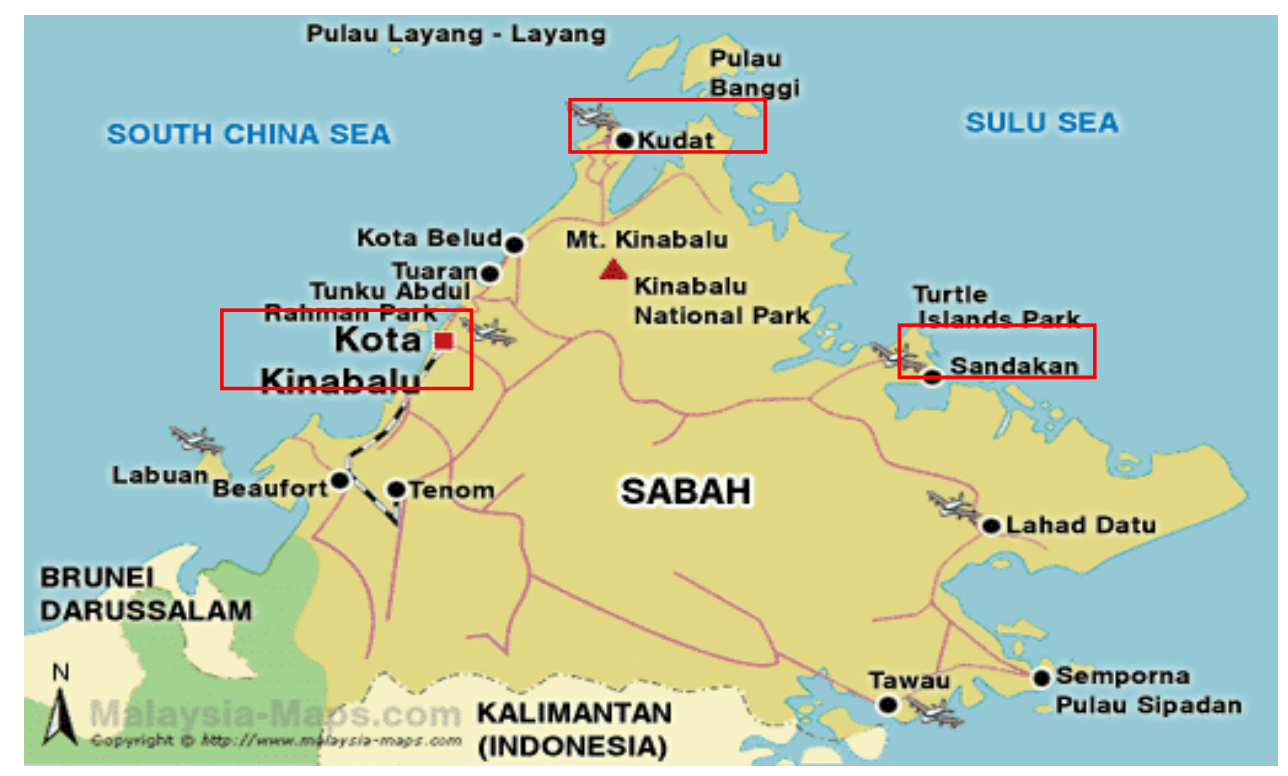

Figure 1. Area: Kudat, Sandakan and Kota Kinabalu.

\section{Methods}

\subsection{Multilayer Perceptron Neural Network (MLP-ANN)}

MLP-ANN is the most used network type among ANN models. The term MLP-ANN is a structure that consists of an input layer, one or more hidden layers and an output layer. Each of the layers 
consists of an inter-connected assembly of simple processing elements called neurons. These processing elements are structured in a layered fashion. Each neuron in a layer is linked to the neuron in the subsequent layer and so on. The interconnections between layers are called weights [31]. Figure 2 shows the architecture of MLP-ANN. The input parameters are moved forward to the network towards nodes in the hidden layer and multiplied with weights of connecting nodes in order to calculate the values of hidden nodes using the transfer function [32] The neurons of the output layer perform a weighted sum using the hidden layer outputs and the weights that connect the hidden layer to the output layer. The number of neurons in each layer may vary depending on the problem. The weighted sum of the input components is calculated as follow:

$$
N e t j=\sum_{i=1}^{n} W i j+\theta j
$$

where $\mathrm{W} i j$ is the weight between the $j$ th neuron and the $i$ th neuron in the proceeding layer and $\theta j$ is the bias term of the $j$ th neuron. The output of the $j$ th neuron out $j$ is calculated with a sigmoid function:

$$
\theta j=f(\text { Net } j) \frac{1}{1+e^{-N e t} j}
$$



Figure 2. Architecture of a multilayer perceptron neural network (MLP-ANN).

\subsection{Adaptive Neuro-Fuzzy Inference System (ANFIS)}

ANFIS applies the hybrid-learning algorithm, which consists of the combination of gradient descent and least squares methods to update the model parameters. Each epoch of this hybrid learning procedure is composed of a forward pass and a backward pass. In the forward pass of the hybrid learning procedure, the node output goes forward until layer 4 . Figure 3 shows the architecture of ANFIS model. More details on the layers can be found in [33]. Next, the consequent parameters are identified by the least squares method. ANFIS uses the Takagi-Sugeno method of inference, and a typical fuzzy rule-for simplicity, there are two inputs parameters ( $x$ and $y$ ) from each scenario and one output $f$. The rule were used in an "if-then" rules of Takagi-Sugeno model, as follows:

$$
\text { If } x \text { is } A \text { and } y \text { is } B \text {, then } z \text { is } f(x, y)
$$

where $A$ and $B$ are the fuzzy sets in the antecedents and $z=f(x, y)$ is a crisp function in the consequent. Usually $f(x, y)$ is a polynomial for the input variables $x$ and $y$. But it can also be any other function that can approximately describe the output of the system within the fuzzy region as specified by the antecedent. When $f(x, y)$ is a constant, a zero order Sugeno fuzzy model is formed which may be considered. 


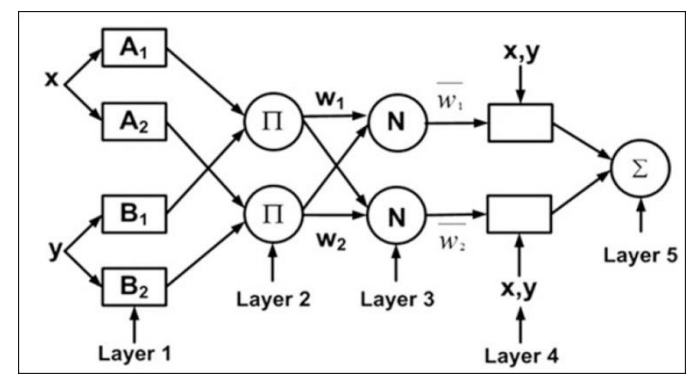

Figure 3. Architecture of an adaptive neuro-fuzzy inference system (ANFIS).

\subsection{Development of the MLP-ANN and ANFIS Models}

An important step in the model development process is data splitting, which can be used to divide the available data into training and testing datasets in order to ensure the models have good generalization ability. Due to the small available dataset, $80 \%$ of the total data were chosen as training data and the remaining $20 \%$ were used as testing data. According to Khatibi (2004), the modeling procedure of time series comprises three major phases [8].

Phase 1: Data review, the selection of suitable software, and splitting data into training (80\%) and testing sets $(20 \%)$.

Phase 2: Applying the time series analysis and running the proposed model.

Phase 3: Post-processing by performing a sensitivity analysis.

Figure 4 illustrates the flow diagram of the prediction methodology of MLP-ANN and ANFIS.

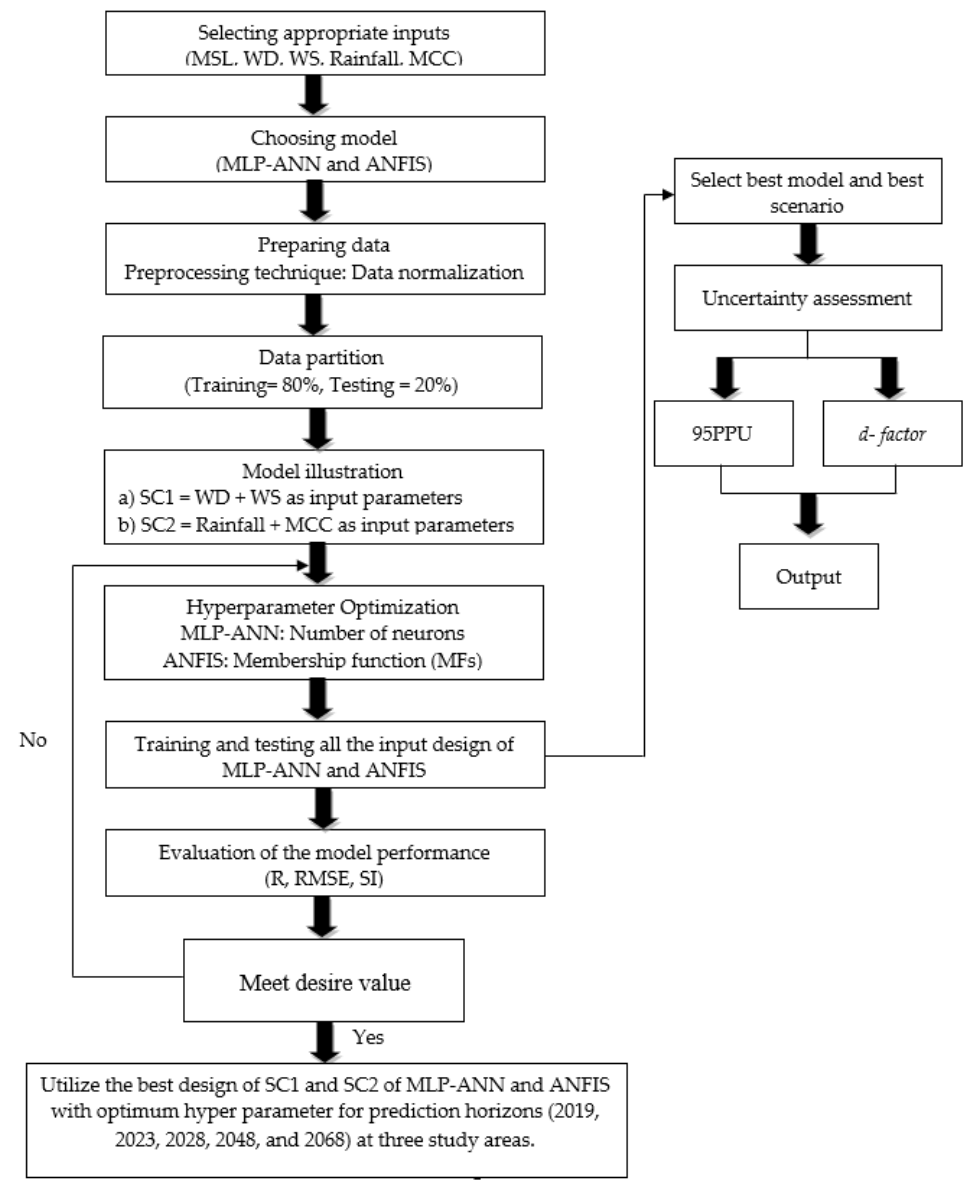

Figure 4. Flow diagram of the prediction methodology of MLP-ANN and ANFIS. 
The proposed model as shown in Figure 4 has been developed in two different stages. The first stage is only to develop the MSL prediction model based on the collected data during the period 2007-2016. In order to complete this stage, the collected data should be split into two parts, the training stage and testing stage $-80 \%$ and $20 \%$, respectively. During training, the model is calibrated using the actual data to predict the MSL after achieving the performance goal. Consequently, the model will be switched to the testing stage, using $20 \%$ of the data (unseen in the training stage) to examine the calibrated model during training using several performance indices. Once the model has successfully achieved the acceptable level of accuracy, the second stage of the whole proposed model can be started to predict MSL-based future information using the pre-developed model and compute the SLR.

\subsection{Selecting Appropriate Inputs}

Selecting appropriate inputs depends on the understanding of the problem. Therefore, the meteorological input parameters must be nominated with care to effectively obtain the proposed model structures. Statistical correlation analysis is a common analytical technique for defining the proper input. Variables of data analysis that were used to select meteorological input parameters were analyzed based on the minimum and maximum value of each meteorological input, total sum, average, standard deviation (SD), and coefficient of variation (CV), which are listed in Table 1 [34].

Table 1. Analysis of meteorological parameter inputs in Kudat, Kota Kinabalu, and Sandakan.

\begin{tabular}{|c|c|c|c|c|c|c|c|c|}
\hline & Location & Statistical & $\begin{array}{c}\text { Mean Sea } \\
\text { Level (MSL) } \\
(\mathrm{mm})\end{array}$ & $\begin{array}{c}\text { Wind } \\
\text { Direction } \\
\text { (WD) }\left({ }^{\circ}\right)\end{array}$ & $\begin{array}{c}\text { Wind } \\
\text { Speed } \\
\text { (WS) }(\mathrm{m} / \mathrm{s})\end{array}$ & $\begin{array}{c}\text { Rainfall } \\
(\mathrm{mm})\end{array}$ & $\begin{array}{c}\text { Mean Cloud } \\
\text { Cover (MCC) } \\
\text { (octas) }\end{array}$ & \multirow{16}{*}{$\begin{array}{l}\text { MONTHLY } \\
\text { INTERVAL }\end{array}$} \\
\hline \multirow{5}{*}{ Kudat } & \multirow{5}{*}{$\begin{array}{l}6^{\circ} 55^{\prime} \mathrm{N} \\
16^{\circ} 50^{\prime} \mathrm{E}\end{array}$} & Min & 6867 & 10.00 & 9.10 & 4.40 & 6.48 & \\
\hline & & Max & 7239 & 360 & 23.10 & 942.40 & 7.37 & \\
\hline & & Average & 7042.88 & 189.92 & 14.43 & 218.00 & 7.01 & \\
\hline & & SD & 76.21 & 91.03 & 2.89 & 189.84 & 0.15 & \\
\hline & & $\mathrm{CV}$ & 1.08 & 47.93 & 20.08 & 87.08 & 2.17 & \\
\hline \multirow{5}{*}{ Sandakan } & \multirow{5}{*}{$\begin{array}{l}5^{\circ} 54^{\prime} \mathrm{N} \\
118^{\circ} 04^{\prime} \mathrm{E}\end{array}$} & Min & 6.48 & 10 & 8.4 & 100.4 & 6.1 & \\
\hline & & Max & 7278 & 370 & 23.4 & 1054.6 & 7.9 & \\
\hline & & Average & 7097.83 & 176.41 & 13.86 & 290.11 & 6.96 & \\
\hline & & $\mathrm{SD}$ & 70.60 & 111.03 & 3.08 & 183.01 & 0.25 & \\
\hline & & $\mathrm{CV}$ & 0.99 & 62.93 & 22.24 & 63.08 & 3.63 & \\
\hline \multirow{5}{*}{$\begin{array}{c}\text { Kota } \\
\text { Kinabalu }\end{array}$} & \multirow{5}{*}{$\begin{array}{l}5^{\circ} 55^{\prime} 57^{\prime \prime} \mathrm{N} \\
116^{\circ} 02^{\prime} 51^{\prime \prime} \mathrm{E}\end{array}$} & Min & 6933 & 10 & 8.8 & 103.8 & 6.75 & \\
\hline & & Max & 7306 & 360 & 24.5 & 593.2 & 7.28 & \\
\hline & & Average & 7099.64 & 190.33 & 14.51 & 267.95 & 7.07 & \\
\hline & & SD & 75.49 & 73.67 & 3.00 & 109.40 & 0.10 & \\
\hline & & $\mathrm{CV}$ & 1.06 & 38.70 & 20.70 & 40.83 & 1.45 & \\
\hline
\end{tabular}

\subsection{Preprocessing Technique}

First, data transformation is applied for data preprocessing. In this study, data normalization was applied as a data transformation technique. It is very important to perform this process because it can help to avoid overflows resulting from a large or very small weight during training. The dataset is normalized by scaling its values such that the dataset falls within a small, specified range from 0 to 1 according to Equation 3, wherein $x$ denotes an input or output value, $\min (x)$ denotes the minimum value of $x$, and $\max (x)$ denotes the maximum value of $x$.

$$
f(v)=\frac{x-\min (x)}{\max (x)-\min (x)}
$$

\subsection{Model Illustration}

The total dataset used herein, which includes historical MSL, WD, WS, rainfall and MCC data, spans a ten-year duration, from 1 January 2007 to 31 December 2016, i.e., 120 months in total, with monthly intervals. Monthly data of the first 8 years from 2007 to 2014 (96 sets or $80 \%$ of the whole dataset) are used for training and monthly data of the last 2 years from 2015 to 2016 (24 sets or $20 \%$ 
of the whole data) are used for testing. Two different scenarios with different combinations of input parameters were implemented for the models. Both scenarios can be expressed in general form as

(a) $\quad$ Scenario $1=$ MSL predicted $=$ Wind direction (observation)) + wind speed (observation)

(b) Scenario 2 = MSL predicted = Rainfall (observation) + mean cloud cover (observation)

\subsection{Performance Criteria}

Three evaluation indices were employed to assess the performance of the proposed models. These indicators are the correlation coefficient (R), root mean square error (RMSE) $\mathrm{mm}$, and scatter index (SI). $x_{i}$ represents the value of the observed MSL at time step $\mathrm{i} ; y_{i}$ denotes the value of the predicted MSL at the same time; $\bar{x}$ denotes the mean value of the observed MSL; $\bar{y}$ denotes the mean value of the predicted MSL; and $\mathrm{n}$ denotes the number of time steps.

$$
\begin{gathered}
R=\frac{\sum_{i=1}^{n}\left(x_{i}-\bar{x}\right) \cdot\left(y_{i}-\bar{y}\right)}{\sqrt{\sum_{i=1}^{n}\left(x_{i}-\bar{x}\right)^{2} \cdot \sum_{i=1}^{n}\left(y_{i}-\bar{y}\right)^{2}}} \\
\operatorname{RMSE}(m m)=\sqrt{\frac{\sum_{i=1}^{n}\left[x_{i}-y_{i}\right]^{2}}{n}} \\
S I=\frac{R M S E}{\underline{x}}
\end{gathered}
$$

\subsection{Uncertainty Analysis}

Uncertainty is a result-dependent factor that demonstrates the range of values a modeling result can attain. It also represents the possibility that the measured value may fall into the specified range. Here, this study applies the method recommended by Abbaspour [35]. The percentage of measured data bracketed by 95 percent of predicted uncertainties (95PPU) is considered. This factor is computed by $2.5 \%(\mathrm{XL})$ and $97.5 \%(\mathrm{XU})$ percentiles.

$$
\text { Bracketed by 95PPU }=\frac{1}{K} \operatorname{Count}(k \mid X L \leq K \leq X U) X 100
$$

where $\mathrm{k}$ is the number of observed data for the testing stages. According to Equation (7), the value of "Bracketed by 95PPU" is maximum (or 100\%) when all observed data for the testing stages are sandwiched between XL and XU. In total, $80 \%-100 \%$ of measured data should be in the 95PPU level, provided that they are of good quality. In some regions, where data are not of good quality, having $50 \%$ of data in the 95PPU level would suffice [35]. Furthermore, to evaluate the average width of confidence interval band, a d-factor parameter has been proposed as Equation (8).

$$
d-\text { factor }=\frac{\overline{d x}}{\sigma x}
$$

where $\sigma \mathrm{X}$ is the standard deviation of the observed data $\mathrm{X}$ and $\overline{\mathrm{dx}}$ is the average distance between the upper and lower bands determined in Equation (9).

$$
\overline{d x}={ }_{k} \sum_{i=1}^{k}(X U-X L)
$$




\section{Result and Discussion}

\subsection{Hyperparameter Optimization of MLP-ANN and ANFIS}

Figure 5 represents the various numbers of neurons used to determine the optimal number of neurons using a trial and error approach. In this study, the Kudat training dataset was selected to show the steps for evaluating the developed model. Several types for training were performed with a variation of $\mathrm{N}=1-15$ neurons. The minimum value of RMSE yielded the best result in choosing the number of neurons.

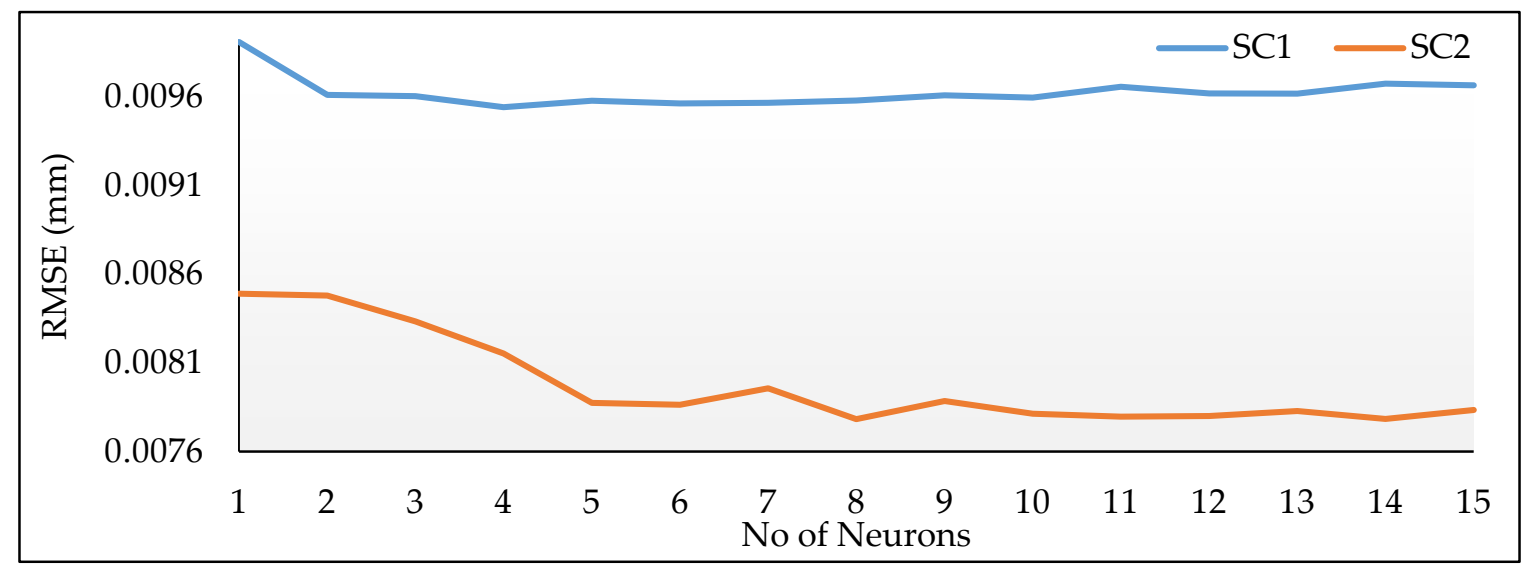

Figure 5. Number of neurons during training.

If a small number of neurons is used, the neural network would perform poorly in capturing the nonlinearity in the data. Based on Figure 5, the performance of RMSE decreased from 0.0095 to 0.0096 $\mathrm{mm}$, while increasing the number of neurons to more than five. Thus, four neurons were selected as the best number in SC1, because that has the minimum RMSE of $0.00954 \mathrm{~mm}$. In contrast, the trend of SC2 shows that increasing the number of neurons to more than nine does not significantly decrease the RMSE. Therefore, eight neurons with an RMSE of $0.00778 \mathrm{~mm}$ were nominated as the best number of neurons and RMSE combination needed for optimal performance.

In developing the ANFIS model, two hyperparameters should be optimized first: the member function (MF) numbers and their shapes. These two hyperparameters are mutually related and determine the level of detail, called the granularity, of the model. A membership function defines the degree of TRUE or FALSE, crisp values, in a range from 0 to 1 . Each membership function contains a curve which represents each point in a specified input partition. Table 2 shows the four types of MFs - triangular, trapezoidal, Gaussian, and generalized bell ( $\mathrm{G}$ bell) that have been trained to determine the best type of MF based on the measured performance of minimum RMSE in SC1 and SC2. The number of considered MFs was either two or three. There is no standard method for determining the number of MFs; hence, the optimal number needs to be found in an iterative manner. However, a large number of MFs should be avoided to save time and computational requirements [36]. Based on Table 1, the best prediction model was obtained using G bell, wherein RMSE values were 0.007502 and $0.007788 \mathrm{~mm}$ for SC1 and SC2, respectively. The worst performance was obtained when the Gaussian model was used. Therefore, it can be concluded that the G bell shape with three MFs can be used for predicting SLR. 
Table 2. Types of member functions (MFs).

\begin{tabular}{cccc}
\hline \multirow{2}{*}{ MF Shape } & MF No. & \multicolumn{2}{c}{ Root Mean Square Error (RMSE) (mm) } \\
\cline { 2 - 4 } & & Scenario1 (SC1) & Scenario2 (SC2) \\
\hline \multirow{2}{*}{ Triangular } & 22 & 0.008964 & 0.010092 \\
& 33 & 0.008084 & 0.009761 \\
Trapezoidal & 22 & 0.008024 & 0.009999 \\
& 33 & 0.007988 & 0.009763 \\
Gaussian & 22 & 0.008132 & 0.009782 \\
& 33 & 0.008061 & 0.009816 \\
G bell & 22 & 0.007892 & 0.008175 \\
& 33 & 0.007502 & 0.007788 \\
\hline
\end{tabular}

\subsection{Preliminary Investigation on the MLP-ANN Model}

Table 3 presents the MLP-ANN results of monthly SLR prediction. Several training algorithms were examined during the training and testing stage in order to evaluate and compare their performances. The algorithms used functions such as Broyden-Fletcher-Goldfarb-Shanno (BFGS), gradient descent (GD), and conjugate gradient Fletcher (CGF) functions. All models were trained for 200 epochs. Column 2 in Table 3 presents the transfer function used in the hidden layer, and column 3 presents the activation function used in the output layer. Following several trials, BFGS performed better than the other models on data from the three stations in both scenarios. By comparing the scenarios, it is clear that SC1 $(2-4-1 ; 2-13-1)$ performs better, in terms of R and RMSE than SC2 on data obtained at Kudat $(\mathrm{R}=0.7904, \mathrm{RMSE}=0.0066 \mathrm{~mm})$ and Sandakan $(\mathrm{R}=0.6773, \mathrm{RMSE}=0.0084 \mathrm{~mm})$ in the test period. However, SC2 (2-13-1) at Kota Kinabalu performed well in terms of R (=0.7497) and RMSE $(=0.0080 \mathrm{~mm})$ than $\mathrm{SC} 1$ in the test period.

Table 3. Testing of various MLP-ANNs.

\begin{tabular}{|c|c|c|c|c|c|c|c|c|c|}
\hline \multirow[b]{2}{*}{ Scenario } & \multirow[b]{2}{*}{ TFHL } & \multirow[b]{2}{*}{ AFOL } & \multirow[t]{2}{*}{ Algo } & \multicolumn{3}{|c|}{ Training } & \multicolumn{3}{|c|}{ Testing } \\
\hline & & & & $\mathbf{R}$ & $\begin{array}{l}\text { RMSE } \\
(\mathrm{mm})\end{array}$ & SI & $\mathbf{R}$ & $\begin{array}{c}\text { RMSE } \\
(\mathrm{mm})\end{array}$ & SI \\
\hline \multicolumn{10}{|l|}{ Kudat } \\
\hline \multirow{3}{*}{$\begin{array}{c}\mathrm{SC} 1 \\
(2-4-1)\end{array}$} & \multirow{3}{*}{ Exp } & \multirow[t]{3}{*}{ Exp } & BFGS & 0.6218 & 0.0084 & 0.0087 & 0.7904 & 0.0066 & 0.0068 \\
\hline & & & GD & 0.6735 & 0.0078 & 0.0080 & 0.7166 & 0.0067 & 0.0069 \\
\hline & & & CGF & 0.6673 & 0.0080 & 0.0080 & 0.7821 & 0.0066 & 0.0068 \\
\hline \multirow{3}{*}{$\begin{array}{c}\text { SC2 } \\
(2-8-1)\end{array}$} & \multirow{3}{*}{$\tanh$} & \multirow[t]{3}{*}{$\log$} & BFGS & 0.3373 & 0.0096 & 0.0099 & 0.6314 & 0.0047 & 0.0048 \\
\hline & & & GD & 0.2757 & 0.0103 & 0.0106 & 0.5623 & 0.0103 & 0.0107 \\
\hline & & & CGF & 0.4298 & 0.0093 & 0.0095 & 0.6222 & 0.0106 & 0.0109 \\
\hline \multicolumn{10}{|l|}{ Sandakan } \\
\hline \multirow{3}{*}{$\begin{array}{c}\text { SC1 } \\
(2-13-1)\end{array}$} & \multirow{3}{*}{$\log$} & \multirow[t]{3}{*}{ Ident } & BFGS & 0.5751 & 0.0079 & 0.0081 & 0.6773 & 0.0084 & 0.0086 \\
\hline & & & GD & 0.5005 & 0.0103 & 0.0106 & 0.6250 & 0.0088 & 0.0091 \\
\hline & & & CGF & 0.6356 & 0.0074 & 0.0076 & 0.6530 & 0.0083 & 0.0086 \\
\hline \multirow{3}{*}{$\begin{array}{c}\text { SC2 } \\
(2-14-1)\end{array}$} & \multirow{3}{*}{$\tanh$} & \multirow[t]{3}{*}{ Exp } & BFGS & 0.4370 & 0.0083 & 0.0085 & 0.5539 & 0.0102 & 0.0105 \\
\hline & & & GD & 0.1973 & 0.0090 & 0.0093 & 0.2786 & 0.0114 & 0.0118 \\
\hline & & & CGF & 0.2649 & 0.0089 & 0.0091 & 0.3848 & 0.0111 & 0.0114 \\
\hline \multicolumn{10}{|l|}{ KK } \\
\hline \multirow{3}{*}{$\begin{array}{c}\text { SC1 } \\
(2-11-1)\end{array}$} & \multirow{3}{*}{$\tanh$} & \multirow[t]{3}{*}{$\log$} & BFGS & 0.3874 & 0.0095 & 0.0098 & 0.4380 & 0.0100 & 0.0104 \\
\hline & & & GD & 0.3858 & 0.0096 & 0.0099 & 0.4145 & 0.0098 & 0.0101 \\
\hline & & & CGF & 0.3856 & 0.0095 & 0.0098 & 0.4336 & 0.0100 & 0.0103 \\
\hline \multirow{3}{*}{$\begin{array}{c}\text { SC2 } \\
(2-13-1)\end{array}$} & \multirow{3}{*}{$\log$} & Ident & BFGS & 0.6933 & 0.0074 & 0.0076 & 0.7497 & 0.0080 & 0.0082 \\
\hline & & & GD & 0.6276 & 0.0102 & 0.0105 & 0.6945 & 0.0098 & 0.0101 \\
\hline & & & CGF & 0.6394 & 0.0078 & 0.0080 & 0.7283 & 0.0080 & 0.0082 \\
\hline
\end{tabular}

$\mathrm{TFHL}=$ transfer function for hidden layer; $\mathrm{AFOL}=$ activation function for output layer; $\mathrm{Log}=$ logistic; Ident $=$ identity; tanh = hyperbolic tangent; Exp = exponential; BFGS = Broyden-Fletcher-Goldfarb-Shanno; GD = gradient descent; CGF = conjugate gradient Fletcher. 


\subsection{Preliminary Investigation on ANFIS Model}

Table 4 presents the ANFIS performance of SLR prediction using the optimal MF for the testing period. Based on Table 4, the result improved by increasing the number of MFs from two to three, yielding the highest $R$ and lowest RMSE values; hence, ANFIS can provide an accurate model for predicting SLR. Comparing SC1 and SC2 reveals that SC1 [3 3] performs better in terms of R and RMSE than SC2 [3 3] on data obtained at Kudat $(R=0.7963$, RMSE $=0.0060 \mathrm{~mm})$ and Sandakan $(R=0.7223$, RMSE $=0.0078 \mathrm{~mm})$ in the test period. However, SC2 [3 3] at Kota Kinabalu performed better than SC1 in terms of $\mathrm{R}(=0.8274)$ and RMSE $(=0.0060 \mathrm{~mm})$ in the test period.

Table 4. Training and testing of various ANFISs.

\begin{tabular}{ccccccccc}
\hline \multirow{2}{*}{ Scenario } & MF & \multicolumn{3}{c}{ Training } & & & Testing \\
\cline { 2 - 8 } & Type & No & R & $\begin{array}{c}\text { RMSE } \\
\mathbf{( m m )}\end{array}$ & SI & R & $\begin{array}{c}\text { RMSE } \\
\text { (mm) }\end{array}$ & SI \\
\hline Kudat & & & & & & & & \\
SC 1 & G bell & 22 & 0.7248 & 0.0078 & 0.0081 & 0.6645 & 0.0059 & 0.0061 \\
& & 33 & 0.8267 & 0.0075 & 0.0077 & 0.7963 & 0.0060 & 0.0062 \\
SC 2 & G bell & 22 & 0.7031 & 0.0081 & 0.0083 & 0.7456 & 0.0089 & 0.0091 \\
& & 33 & 0.7078 & 0.0077 & 0.0079 & 0.7534 & 0.0087 & 0.0090 \\
\hline Sandakan & & & & & & & & \\
SC 1 & G bell & 22 & 0.5000 & 0.0078 & 0.0080 & 0.4254 & 0.0086 & 0.0088 \\
& & 33 & 0.7725 & 0.0070 & 0.0072 & 0.7223 & 0.0078 & 0.0080 \\
SC 2 & G bell & 22 & 0.5888 & 0.0074 & 0.0076 & 0.5672 & 0.0081 & 0.0083 \\
& & 33 & 0.6615 & 0.0067 & 0.0069 & 0.6940 & 0.0074 & 0.0076 \\
\hline KK & & & & & & & & \\
SC 1 & G bell & 22 & 0.5434 & 0.0086 & 0.0089 & 0.4164 & 0.0095 & 0.0098 \\
& & 33 & 0.6347 & 0.0078 & 0.0080 & 0.7686 & 0.0068 & 0.0070 \\
SC 2 & G bell & 22 & 0.7172 & 0.0072 & 0.0074 & 0.7223 & 0.0065 & 0.0067 \\
& & 33 & 0.7375 & 0.0069 & 0.0071 & 0.8274 & 0.0060 & 0.0062 \\
\hline
\end{tabular}

A comparison between the developed MLP-ANN and the ANFIS obtained from the best scenario is shown in Figures 6-8. Figure 6 shows the scatter diagram of training and testing at Kudat; Figure 7 presents the Sandakan scatter diagram of training and testing; and Figure 8 shows the training and testing at Kota Kinabalu station.
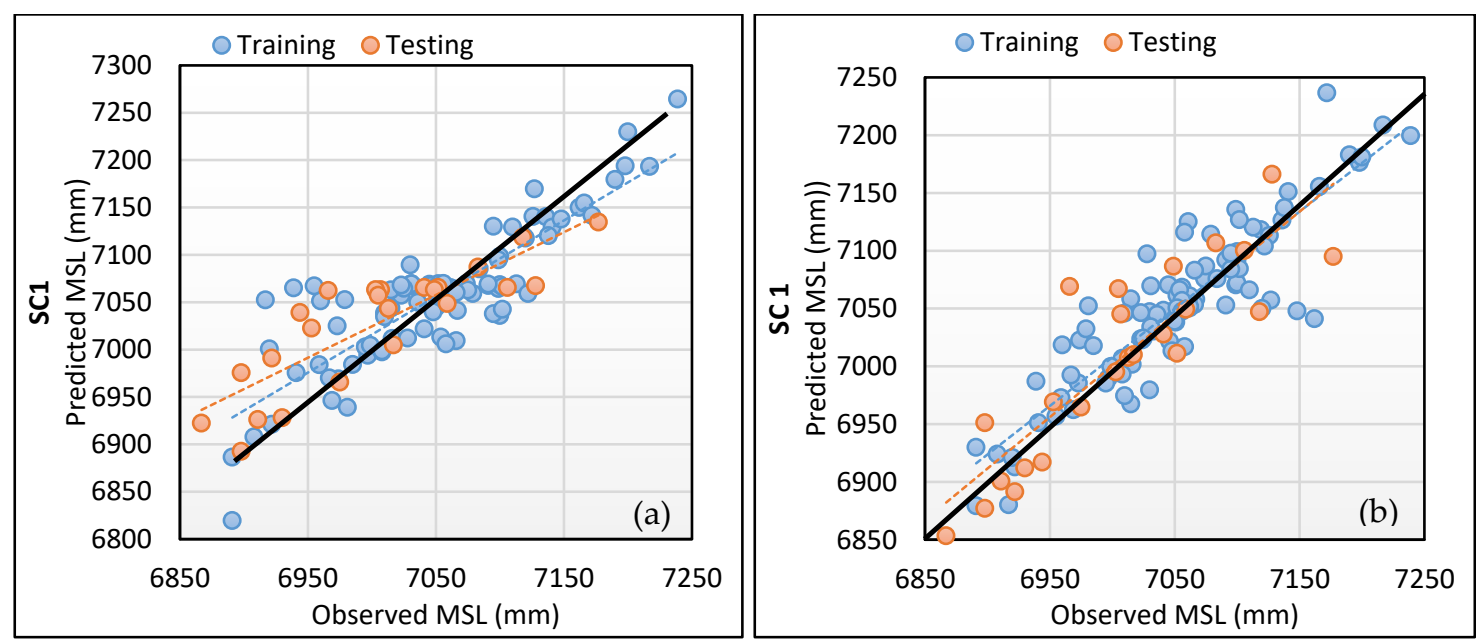

Figure 6. Plots for SC1 at Kudat: (a) MLP-ANN and (b) ANFIS. 

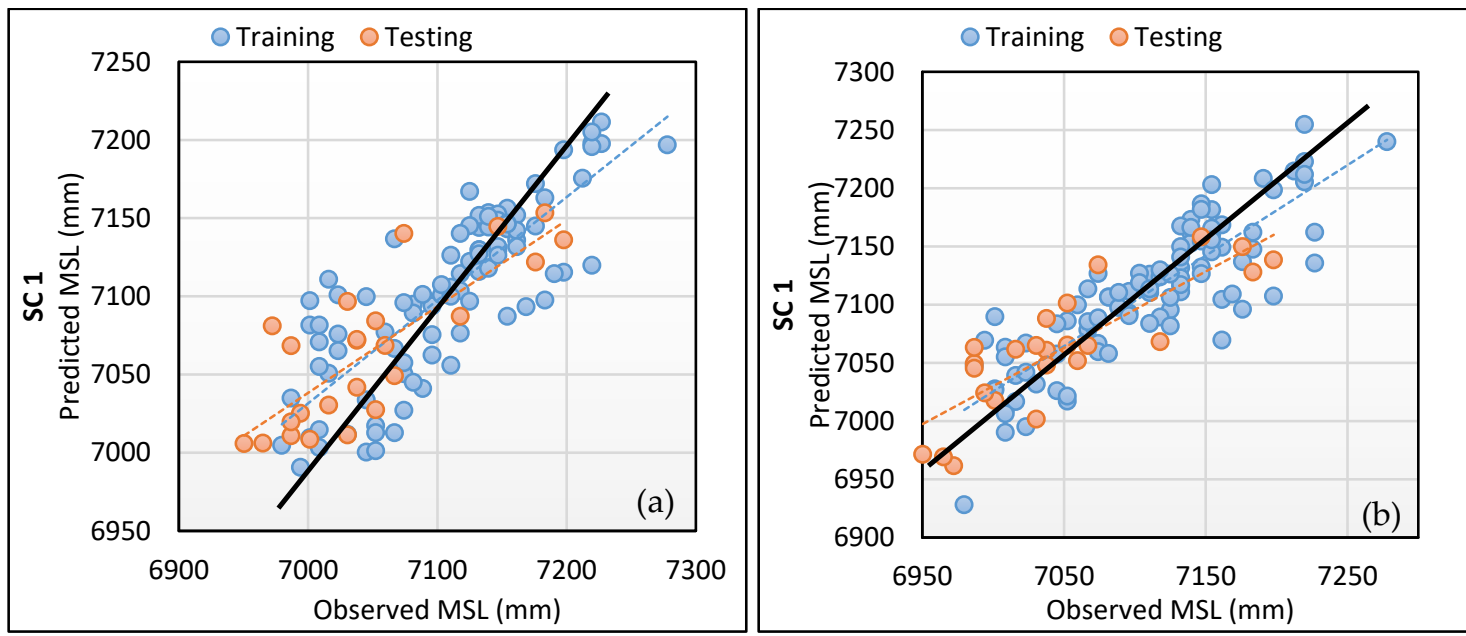

Figure 7. Plots for SC1 at Sandakan: (a) MLP-ANN and (b) ANFIS.


Figure 8. Plots for SC2 at Kota Kinabalu: (a) MLP-ANN and (b) ANFIS.

The scatter plots of the training and testing MSL at Kudat station in Figure 6 show that the MLP-ANN and ANFIS models can effectively predict SLR. However, the MLP-ANN model outperforms the ANFIS model (approximately $0.740 \%$ improvement) in SC1. Furthermore, the ANFIS plot passed through the origin.

Figure 7 shows a comparison between the training and testing for SC1 in Sandakan. It can be seen that the ANFIS performed better than MLP-ANN (approximately $6.23 \%$ improvement). We observed that the ANFIS model can depict the behavior of the MSL pattern more accurately than MLP-ANN in both the training and testing stage. Most predicted values are close to the observed MSL.

Scatter plots of the training and testing at Kota Kinabalu station in Figure 8 show that the MLP-ANN and ANFIS models can be used to predict SLR. ANFIS outperformed MLP-ANN (approximately 9.39\% improvement) in SC2. In addition, the ANFIS plot of the predicted values is sufficiently close to satisfy the verification criteria. Thus, the ANFIS model outperformed the MLP-ANN model, performed better in both the training and testing stage and has a better scattered and linear fitting of predicted MSL with observed MSL than the MLP-ANN model.

\subsection{Uncertainty Analysis of the ANFIS Model}

Uncertainty analysis of the best ANFIS model was calculated by using two criteria, namely 95PPU and d-factor, such that the increase in observed data in 95PPU level and the decrease in average value 
of upper and lower bands (smaller than the standard deviation of the measured data) in uncertainty eventuate in a more favorable uncertainty for testing datasets are given in Table 5 . The values bracketed by $95 \mathrm{PPU}$ indicate approximately $75.2 \%, 77.4 \%$ and $76.8 \%, 91.6 \%$ of data for the best scenario for Kudat, Sandakan and Kota Kinabalu stations, respectively. Furthermore, the d-factor has a value of $0.27,0.21$ and 0.23 for Kudat, Sandakan and Kota Kinabalu stations, respectively. Based on the obtained values in both stations for 95PPU and d-factor indices, it can be concluded that all the observed data fall into the 95PPU band range (over 50\% of observed data).

Table 5. Analysis of the ANFIS model.

\begin{tabular}{cccc}
\hline Station & Best Scenario & Statistic & ANFIS \\
\hline Kudat & SC1 & $95 P P U$ & 75.2 \\
& & $d$-factor & 0.27 \\
Sandakan & SC1 & $95 P P U$ & 77.4 \\
& & $d$-factor & 0.21 \\
Kota Kinabalu & SC2 & $95 P P U$ & 76.8 \\
& & $d$-factor & 0.23 \\
\hline
\end{tabular}

\subsection{SLR Prediction in Different Year Horizons}

The need for effective SLR prediction is vital, especially for coastal areas and offshore structures. Herein, the MLP-ANN and ANFIS models were used for SLR prediction at different times, in the years $2019,2023,2028,2048$, and 2068, for three stations, using the two proposed scenarios. The predicted SLR rates obtained using MLP-ANN and the observed SLR rates are shown in Table 6 for both SC1 and SC2. In general, the observed mean rate is lower than the predictions obtained using SC1 and SC2 for the period ranging from 2019 to 2068. In the observed year, the mean SLR rate at Kudat, Sandakan, and Kota Kinabalu is 7043, 7098, and 7099 mm/yr, respectively. The mean values of the SLR rate predictions on the data obtained from Kudat and Sandakan for SC1 are higher than those obtained for SC2, whereas, the mean value of the SLR rate predictions on data obtained from Kota Kinabalu for SC2 is higher than that obtained for SC1. In 2019, the highest SLR in SC1 occurred in Kudat, with a mean rate of $7037 \mathrm{~mm} / \mathrm{yr}$ and confidence interval of 6924 to $7118 \mathrm{~mm} / \mathrm{yr}$, followed by Sandakan, with a mean rate of $7094 \mathrm{~mm} / \mathrm{yr}$ and confidence interval of 7028-7153 mm/yr. In 2019, the highest SLR in Kota Kinabalu for SC2 has a mean rate of $7105 \mathrm{~mm} / \mathrm{yr}$ and a confidence interval of $7003-7183 \mathrm{~mm} / \mathrm{yr}$. The same SLR prediction trend continued in 2023, 2028, 2048, and 2068. The MSL is predicted to be 7045, 7098, and $7099 \mathrm{~mm} / \mathrm{yr}$ and 7042, 7097, $7110 \mathrm{~mm} / \mathrm{yr}$ for SC1 and SC2, respectively, in 2068 for the three different stations. Based on these trends, it is notable that the MSL rate is rising over the period considered.

Predicted SLR rates obtained using ANFIS and the observed rates are presented in Table 7 for both SC1 and SC2. In 2019, the highest value of SLR in SC1 occurred in Kudat rather than in SC2, with a mean of $7039 \mathrm{~mm} / \mathrm{yr}$ and a confidence interval of 6941 to $7111 \mathrm{~mm} / \mathrm{yr}$. In contrast, SC1 also produced the highest value of SLR at Sandakan, with a mean of $7097 \mathrm{~mm} / \mathrm{yr}$ and a confidence interval of 7045 to $7191 \mathrm{~mm} / \mathrm{yr}$, compared to SC2. Therefore, the SLR projection is considerably higher in Kudat and Sandakan using WD and WS as inputs. However, the SLR rate prediction obtained for Kota Kinabalu using SC1 as an input parameter is considerably lower than that obtained using SC2 as an input parameter because including WD and WS as an input does not have much impact on the SLR. This is evidenced by the mean rate of $7107 \mathrm{~mm} / \mathrm{yr}$ and confidence interval of 7028 to $7192 \mathrm{~mm} / \mathrm{yr}$ in SC2. The SLR prediction trend continued throughout 2023, 2028, 2048, and 2068. In 2068, The MSL in SC1 is predicted to be 7048, 7099, and $7100 \mathrm{~mm} / \mathrm{yr}$ and 7044, 7099, $7119 \mathrm{~mm} / \mathrm{yr}$ in SC2 at different stations. Based on these trends, it is notable that the increment rate of change of MSL is on the rise. This increment is considered to contribute to the rise in sea level. The results of [37] report that, by the year 2050 , the sea level will increase $\sim 0.12 \mathrm{~m}$ according to linear regression results, whereas a 0.32 
$\mathrm{m}$ rise in sea level has been predicted using quadratic regression. However, these models used only 35 years of tide measurements, which might not be sufficient for SLR prediction up to 2050.

Table 6. SLR rate (mm/yr) in different year horizons for SC1 and SC2 using MLP-ANN. (LL: lower limit; UL: upper limit; AV: average change in sea level).

\begin{tabular}{|c|c|c|c|c|c|c|c|c|c|c|c|}
\hline \multicolumn{12}{|c|}{ Year Horizon } \\
\hline & \multirow[t]{2}{*}{ Observed Year } & \multicolumn{2}{|c|}{2019} & \multicolumn{2}{|c|}{2023} & \multicolumn{2}{|c|}{2028} & \multicolumn{2}{|c|}{2048} & \multicolumn{2}{|c|}{2068} \\
\hline & & SC1 & SC2 & SC1 & SC2 & SC1 & SC2 & SC1 & SC2 & SC1 & SC2 \\
\hline \multicolumn{12}{|c|}{ Kudat } \\
\hline LL & 6867 & 6924 & 6908 & 6938 & 6906 & 6955 & 6895 & 6951 & 6886 & 6955 & 6899 \\
\hline UL & 7039 & 7118 & 7063 & 7078 & 7106 & 7096 & 7106 & 7177 & 7079 & 7179 & 7137 \\
\hline Mean & 7043 & 7037 & 7023 & 7042 & 7050 & 7045 & 7043 & 7043 & 7042 & 7045 & 7042 \\
\hline AV & 13.6 & 18.0 & 4.0 & 25.3 & 6.7 & 17.3 & 6.0 & 18.8 & 11.2 & 17.5 & 19.4 \\
\hline \multicolumn{12}{|c|}{ Sandakan } \\
\hline LL & 6954 & 7028 & 7009 & 7031 & 6993 & 6995 & 7010 & 7004 & 6989 & 7001 & 6968 \\
\hline UL & 7178 & 7153 & 7174 & 7201 & 7186 & 7278 & 7219 & 7209 & 7223 & 7226 & 7201 \\
\hline Mean & 7098 & 7094 & 7088 & 7108 & 7107 & 7101 & 7100 & 7098 & 7098 & 7098 & 7097 \\
\hline AV & 16.9 & 19.0 & 13.0 & 25.5 & 27.5 & 15.0 & 13.0 & 15.0 & 18.0 & 17.0 & 15.0 \\
\hline \multicolumn{12}{|c|}{ Kota Kinabalu } \\
\hline LL & 6933 & 6978 & 7003 & 6982 & 6967 & 6859 & 7002 & 6926 & 7007 & 6932 & 6992 \\
\hline UL & 7106 & 7121 & 7183 & 7150 & 7151 & 7104 & 7180 & 7139 & 7220 & 7148 & 7251 \\
\hline Mean & 7099 & 7098 & 7105 & 7107 & 7108 & 7103 & 7101 & 7100 & 7100 & 7099 & 7100 \\
\hline AV & 22.0 & 17.0 & 10.0 & 26.0 & 16.3 & 0.12 & 14.7 & 8.8 & 20.2 & 13.0 & 24.8 \\
\hline
\end{tabular}

Table 7. SLR rate (mm/yr) for different years for SC1 and SC2 using ANFIS. (LL: lower limit; UL: upper limit; AV: average change in sea level).

\begin{tabular}{|c|c|c|c|c|c|c|c|c|c|c|c|}
\hline \multicolumn{12}{|c|}{ Year Horizon } \\
\hline & Observed Year & \multicolumn{2}{|c|}{2019} & \multicolumn{2}{|c|}{2023} & \multicolumn{2}{|c|}{2028} & \multicolumn{2}{|c|}{2048} & \multicolumn{2}{|c|}{2068} \\
\hline & & SC1 & SC2 & SC1 & SC2 & SC1 & SC2 & SC1 & SC2 & SC1 & $\mathrm{SC2}$ \\
\hline \multicolumn{12}{|c|}{ Kudat } \\
\hline LL & 6867 & 6941 & 6888 & 6902 & 6898 & 6902 & 6897 & 6924 & 6892 & 6942 & 6893 \\
\hline UL & 7039 & 7111 & 7074 & 7171 & 7093 & 7161 & 7138 & 7178 & 7114 & 7165 & 7140 \\
\hline Mean & 7043 & 7039 & 7027 & 7044 & 7051 & 7046 & 7046 & 7047 & 7043 & 7048 & 7044 \\
\hline AV & 13.6 & 14.0 & 7.0 & 28.0 & 13.8 & 18.0 & 7.4 & 16.0 & 8.4 & 18.0 & 10.0 \\
\hline \multicolumn{12}{|c|}{ Sandakan } \\
\hline LL & 6954 & 7045 & 7030 & 7033 & 7032 & 7031 & 7002 & 7028 & 6982 & 7029 & 6991 \\
\hline UL & 7178 & 7191 & 7156 & 7223 & 7212 & 7283 & 7174 & 7229 & 7210 & 7234 & 7213 \\
\hline Mean & 7098 & 7097 & 7095 & 7110 & 7111 & 7113 & 7112 & 7099 & 7110 & 7099 & 7099 \\
\hline AV & 16.9 & 20.0 & 22.0 & 17.3 & 15.8 & 17.7 & 15.0 & 22.0 & 14.2 & 13.5 & 12.3 \\
\hline \multicolumn{12}{|c|}{ Kota Kinabalu } \\
\hline LL & 6933 & 6987 & 7028 & 6942 & 6995 & 6907 & 7007 & 6917 & 7011 & 6928 & 6994 \\
\hline UL & 7106 & 7137 & 7192 & 7201 & 7209 & 7203 & 7224 & 7215 & 7230 & 7215 & 7289 \\
\hline Mean & 7099 & 7103 & 7107 & 7108 & 7110 & 7109 & 7108 & 7118 & 7118 & 7100 & 7119 \\
\hline $\mathrm{AV}$ & 22.0 & 12.0 & 8.0 & 25.0 & 18.8 & 21.2 & 14.1 & 18.1 & 18.3 & 18.3 & 27.9 \\
\hline
\end{tabular}

For better illustration, Figure 9 shows the differences in trends between the LL, UL, and their mean from 2019 to 2068 ahead of the ones obtained from the best scenario at each station. 

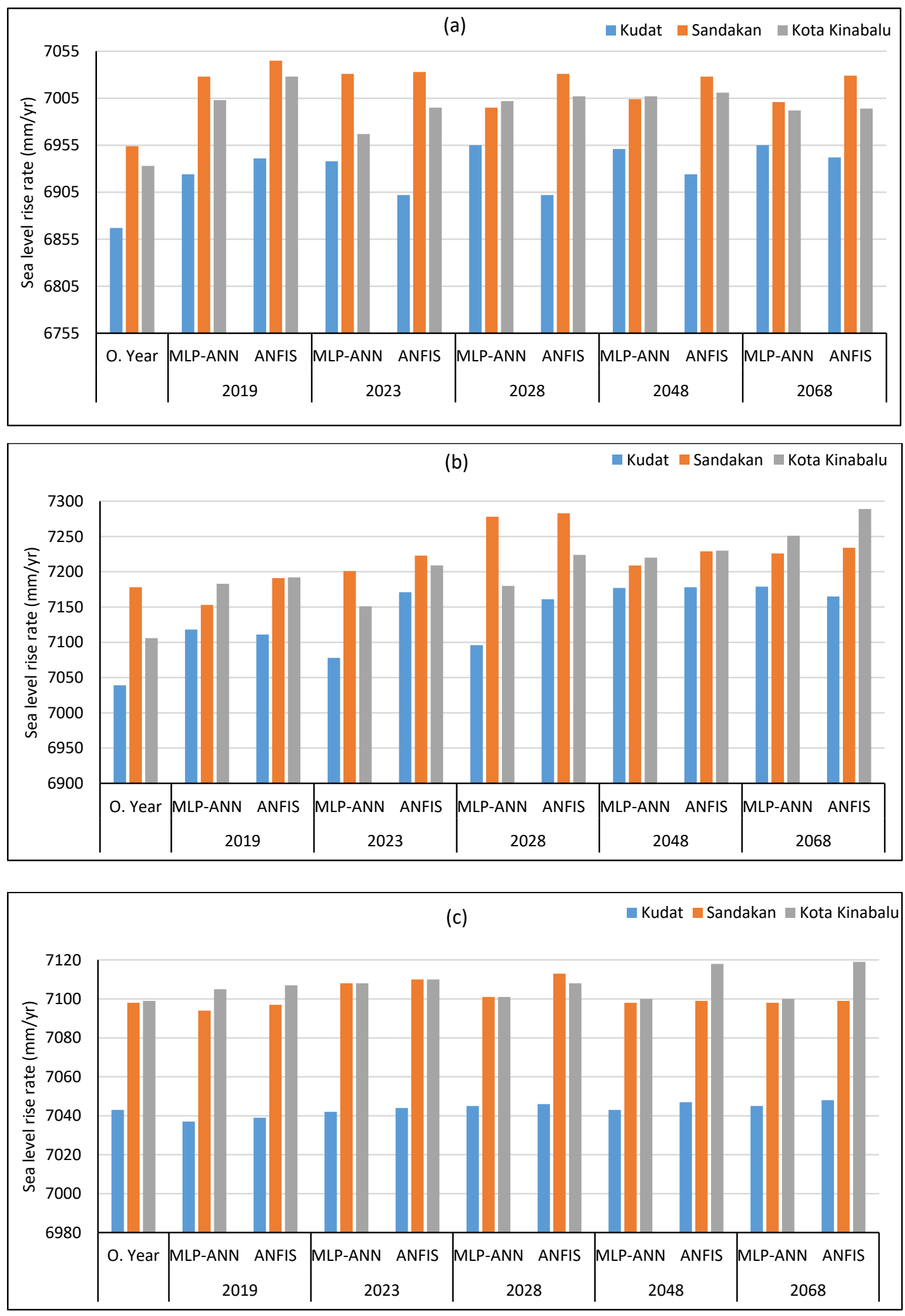

Figure 9. SLR rate (mm/yr) prediction using MLP-ANN and ANFIS on data obtained from Kudat, Sandakan, and Kota Kinabalu: (a) lower limit, (b) upper limit, and (c) the mean.

\section{Conclusions and Recommendations}

This study investigated the impact of meteorological parameters on SLR prediction for Kudat, Sandakan, and Kota Kinabalu stations in the Sabah state of Malaysia. These meteorological parameters 
are WD, WS, rainfall, and MCC. Two scenarios with different input combinations were proposed. The capability of AI techniques such as MLP-ANN in performing such predictions were tested and compared with the results obtained using the ANFIS model. Two different scenarios were considered (SC1 and SC2) and their results were compared. As a preliminary step, the models were developed and optimized using the optimal input to obtain the best combination of parameters to be used in predicting sea levels in 2019, 2023, 2028, 2048, and 2068. In MLP-ANN, several models were developed with a varying range of neurons $(\mathrm{N}=1-15)$ using a trial and error approach to determine the best number of neurons for both scenarios. The best number of neurons was found to be equal to 4 and 8 at Kudat, 13 and 14 at Sandakan, and 11 and 13 at Kota Kinabalu. Three different training algorithms were tested: BFGS, GD, and CGF. We discovered that BFGS outperformed all other training algorithms for all stations. Regarding ANFIS, various membership functions were investigated, and we discovered that the G bell MF is the best model for accurately predicting SLR. A comparison between the developed MLP-ANN method and the ANFIS method shows that the ANFIS method exhibited higher accurate performance in the training and testing stage for both scenarios. Additionally, the reliability of the ANFIS model prediction was calculated by an uncertainty estimation. Based on the values in all stations for the 95PPU and d-factor indices, it is concluded that the ANFIS model has an acceptably low degree of uncertainty applied for SC1 and SC2 simulations. Furthermore, the proposed models were applied to predict SLR for different periods: 2019, 2023, 2028, 2048, and 2068. By comparing the two scenarios, we observed that the predicted SLR for different time periods was higher for SC1 in Kudat and Sandakan in terms of LL, UL, mean, and average changes in sea level. One of the factors for this is that Kudat and Sandakan are located close to an open sea (the Sulu Sea). Winds are known to be among the most important parameters for forcing sea level variability on the eastern margins of the ocean and play a role by moving warm water from one place to another. In contrast, we observed that the predicted SLR was higher for the Kota Kinabalu data in SC2. This is attributed to the location of Kota Kinabalu, which is classified as an equatorial climate region, with high humidity, a considerable amount of sunlight, and abundant rainfall, which are relatively high and extremely invariable parameters throughout the year. This study considered only two input parameters for each scenario is because to minimize the input combination without losing the accuracy of the model performance.

Both the proposed models are appropriate for predicting SLR in different time horizons without bias or eliminating the hidden information. The results obtained from this study provide reliable prediction values with respect to the future increase in sea level in the chosen coastal areas. In addition, the findings of this study showed that including only two input meteorological parameters for each scenario can have a profound influence on the predicted sea level. Therefore, this study shows that the model can be used if there is shortage in data availability, which is very common in Malaysia and surely will help various authorities in managing possible damage that may occur in coastal areas of Malaysia. Conducting future research to perform further analysis on the sensitivity between each input variable with the associated output and identifying the weight matrix could be a potential future research direction. Future studies may also focus on improving the proposed model by introducing other complex parameters as the model input, which has not been investigated in this study because of the limitation of the available data.

Author Contributions: Formal analysis, T.O.M.; Resources, H.A.A.; Supervision, A.N.A. and M.S. (Mohsen Sherif); Validation, A.E.-S. (Ahmed El-Shafie) and A.S.; Writing-original draft, M.A.M.; Writing-review and editing, R.K.I., M.S. (Michelle Sapitang) and A.E.-S. (Amr El-Shafie). All authors have read and agreed to the published version of the manuscript.

Funding: This research was funded by RESEARCH GRANT OPEX, grant number RJO10436494, iRMC Bold 2025, Universiti Tenaga Nasional.

Acknowledgments: Universiti Tenaga Nasional supported the research presented in this article under RESEARCH GRANT OPEX, grant number RJO10436494, iRMC Bold 2025, Universiti Tenaga Nasional. We wish to thank the Malaysian Meteorological Department (MetMalaysia) for providing data for this research.

Conflicts of Interest: The authors declare no conflict of interest. 


\section{References}

1. Douglas, B.C. Global Sea Rise: A Redetermination. Surv. Geophys. 1997, 18, 279-292. [CrossRef]

2. Douglas, B.C. An Introduction to Sea-Level. In Sea-Level Rise History and Consequences; Douglas, B.C., Kearney, M.F., Leatherman, S.P., Eds.; Academic Press: New York, NY, USA, 2000; pp. 1-11.

3. Anthony, D.; Shaaban, A.; Aung, T.H.; Saleh, E.; Hamid, R.A.; Osman, A. Sea Level Changes Along the Coast of Sandakan Town, Sabah, Malaysia: Projection and Inundation Coverage. In Proceedings of the E-Proceedings of the 36th IAHR World Congress, Hague, The Netherlands, 28 June-3 July 2015.

4. Sujahangir, M.; Begum, R.; Pereira, J.; Jaafar, A.; Saari, M. Impacts of and Adaptations to Sea Level Rise in Malaysia. Asian J. Water Environ. Pollut. 2014, 11, 29-36.

5. Pasquali, D.; Di Risio, M.; De Girolamo, P. A simplified real time method to forecast semi-enclosed basins storm surge. Estuar. Coast. Shelf Sci. 2015, 165, 61-69. [CrossRef]

6. Franco, A. Tides-Fundamentals, Analysis and Prediction. Ocean. Eng. 1982, 9, 407-408. [CrossRef]

7. Meena, B.; Agrawal, J. Tidal Level Forecasting Using ANN. Procedia Eng. 2015, 116, 607-614. [CrossRef]

8. Karimi, S.; Kisi, O.; Shiri, J.; Makarynskyy, O. Neuro-fuzzy and Neural Network Techniques for Forecasting Sea Level in Darwin Harbor, Australia. Comput. Geosci. 2013, 52, 50-59. [CrossRef]

9. Awang, N.; Abd Hamid, M. Sea Level Rise in Malaysia. IAHR 2013, 2, 47-49.

10. Mimura, N. Sea-level rise caused by climate change and its implications for society. Proc. Jpn. Acad. Ser. B Phys. Biol. Sci. 2013, 89, 281-301. [CrossRef]

11. Muslim, T.; Ahmed, A.N.; Malek, M.A.; El-Shafie, A.; El-Shafie, A. Investigating the Impact of Wind on Sea Level Rise Using Multilayer Perceptron Neural Network (MLP-NN) at Coastal Area, Sabah. Int. J. Civ. Eng. Technol. 2019, 6, 80-92.

12. Sturges, W.; Douglas, B. Wind effects on estimates of sea level rise. J. Geophys. Res. 2011, 116. [CrossRef]

13. Filippo, A.; Torres, A.R.; Kjerfve, B.; Monat, A. Application of Artificial Neural Network (ANN) to Improve Forecasting of Sea Level. Ocean. Coast. Manag. 2012, 55, 101-110. [CrossRef]

14. Pelikan, P.; Markova, J. Wind Effect on Water Surface of Water Reservoirs. Acta Univ. Agric. Silvic. Mendel. Brun. 2013, 61, 1823-1828. [CrossRef]

15. Ghorbani, M.A.; Makarynskyy, O.; Shiri, J.; Makarynska, D. Genetic Programming for Sea Level Predictions in an Island Environment. Int. J. Ocean. Clim. Syst. 2010, 1, 27-35. [CrossRef]

16. Sztobryn, M. Application of Artificial Neural Network into the Water Level Modeling and Forecast. TransNav Int. J. Mar. Navig. Saf. Sea Transp. 2013, 7, 219-223. [CrossRef]

17. Ketabchi, H.; Mahmoodzadeh, D.; Ataie-Ashtiani, B.; Simmons, C. Sea-level Rise Impacts on Seawater Intrusion in Coastal Aquifers: Review and Integration. J. Hydrol. 2016, 535, 235-255. [CrossRef]

18. Laura, T.; Beverly, P.; Maneja, R.; Radjawane, I. Sea Level Rise Vulnerability of Southeast Asian Coasts. Sci. Highlights 2008, 3-6. Available online: https://www.researchgate.net/publication/281267072 (accessed on 18 September 2019).

19. Gutierrez, B.; Plant, N.; Thieler, E. A Bayesian Network to Predict Coastal Vulnerability to Sea Level Rise. J. Geophys. Res. Earth Surf. 2011, 116. [CrossRef]

20. Song, J.; Peng, B. Should We Leave? Attitudes towards Relocation in Response to Sea Level Rise. Water 2017, 9, 941. [CrossRef]

21. Makarynskyy, O.; Makarynska, D.; Kuhn, M.; Featherstone, W. Predicting Sea Level Variations with Artificial Neural Networks at Hillarys Boat Harbour, Western Australia. Estuar. Coast. Shelf Sci. 2004, 61, 351-360. [CrossRef]

22. Herbich, J. Handbook of Coastal and Ocean Engineering; Gulf Pub.: Houston, TX, USA, 1992.

23. Chen, S.; Jakeman, A.; Norton, J. Artificial Intelligence Techniques: An Introduction to their Use for Modelling Environmental Systems. Math. Comput. Simul. 2008, 78, 379-400. [CrossRef]

24. Alvisi, S.; Mascellani, G.; Franchini, M.; Bardossy, A. Water Level Forecasting through Fuzzy Logic and Artificial Neural Network Approaches. Hydrol. Earth Syst. Sci. 2006, 10, 1-17. [CrossRef]

25. Nitsure, S.; Londhe, S.; Khare, K. Prediction of Sea Water Levels using Wind Information and Soft Computing Techniques. Appl. Ocean. Res. 2014, 47, 344-351. [CrossRef]

26. Piri, J.; Kahkha, M. Prediction of Water Level Fluctuations of Chahnimeh Reservoirs in Zabol Using ANN, ANFIS and Cuckoo Optimization Algorithm. Iran. J. Health Saf. Environ. 2017, 4, 706-715. 
27. Kaloop, M.; El-Diasty, M.; Hu, J. Real-time Prediction of Water Level Change using Adaptive Neuro-Fuzzy Inference System. Geomat. Nat. Hazards Risk 2017, 8, 1320-1332. [CrossRef]

28. Chang, F.; Chang, Y. Adaptive Neuro-Fuzzy Inference System for Prediction of Water Level in Reservoir. Adv. Water Resour. 2006, 29, 1-10. [CrossRef]

29. Chang, F.; Lai, H. Adaptive Neuro-Fuzzy Inference System for the Prediction of Monthly Shoreline Changes in Northeastern Taiwan. Ocean. Eng. 2014, 84, 145-156. [CrossRef]

30. Pashova, L.; Popova, S. Daily Sea Level Forecast at Tide Gauge Burgas, Bulgaria using Artificial Neural Networks. J. Sea Res. 2011, 66, 154-161. [CrossRef]

31. Moon, J.; Kim, K.; Min, H. ANN-Based Prediction and Optimization of Cooling System in Hotel Rooms. Energies 2015, 8, 10775-10795. [CrossRef]

32. Alam Mia, M.; Biswas, S.; Urmi, M.; Siddique, A. An Algorithm for Training Multilayer Perceptron (MLP) For Image Reconstruction Using Neural Network without Overfitting. Int. J. Sci. Technol. Res. 2015, 2, 271-275.

33. Buragohan, M. Adaptive Network Based Fuzzy Inference System (ANFIS) as a Tool for System Identification with Special Emphasis on Training Data Minimization. Ph.D. Thesis, Institute of Tech Guwathi, Guwathi, India, 2008.

34. Yahya, A.S.A.; Ahmed, A.N.; Othman, F.B.; Ibrahim, R.K.; Afan, H.A.; El-Shafie, A.; Fai, C.M.; Hossain, M.S.; Ehteram, M.; Elshafie, A. Water Quality Prediction Model Based Support Vector Machine Model for Ungauged River Catchment under Dual Scenarios. Water 2019, 11, 1231. [CrossRef]

35. Abbaspour, K.C.; Yang, J.; Maximov, I.; Siber, R.; Bogner, K.; Mieleitner, J.; Zobrist, J.; Srinivasan, R. Modeling hydrology and water quality in the pre-alpine/alpine Thur watershed using SWAT. J. Hydrol. 2007, 333, 413-430. [CrossRef]

36. Keskin, M.; Terzi, O.; Taylan, D. Fuzzy Logic Model Approaches to Daily Pan Evaporation Estimation in Western Turkey. Hydrol. Sci. J. 2004, 49. [CrossRef]

37. Chun, J.; Lim, C.; Kim, D.; Kim, J. Assessing Impacts of Climate Change and Sea-Level Rise on Seawater Intrusion in a Coastal Aquifer. Water 2018, 10, 357. [CrossRef]

(C) 2020 by the authors. Licensee MDPI, Basel, Switzerland. This article is an open access article distributed under the terms and conditions of the Creative Commons Attribution (CC BY) license (http://creativecommons.org/licenses/by/4.0/). 